\title{
Determinants of Age at First Birth of Bangladeshi Women: A Multivariate Approach on DHS 2014 Data
}

\author{
Shanjida Chowdhury ${ }^{1}$, Mahfujur Rahman ${ }^{2}$, Nurul Mohammad Zayed ${ }^{3, *}$, Shahiduzzaman Khan Shahi ${ }^{3}$ \\ ${ }^{1}$ Department of General Educational Development, Daffodil International University, Bangladesh. \\ ${ }^{2}$ Comilla University Kotbari, Cumilla-3506, Bangladesh. \\ ${ }^{3}$ Department of Real Estate, Faculty of Business \& Entrepreneurship, Daffodil International University, Bangladesh.
}

\begin{abstract}
How to cite this paper: Shanjida Chowdhury, Mahfujur Rahman, Nurul Mohammad Zayed, Shahiduzzaman Khan Shahi. (2020) Determinants of Age at First Birth of Bangladeshi Women: A Multivariate Approach on DHS 2014 Data. Journal of Humanities, Arts and Social Science, 4(2), 118-125. DOI: $10.26855 /$ jhass.2020.07.006
\end{abstract}

Received: September 1, 2020

Accepted: September 28, 2020

Published: October 23, 2020

*Corresponding author: Nurul Mohammad Zayed, Department of Real Estate, Faculty of Business \& Entrepreneurship, Daffodil International University, Bangladesh.

Email: Zayed.bba@daffodilvarsity.edu.bd

\begin{abstract}
First birth is a step towards a woman's motherhood, and is one of the important indicators of maternal health. It also has an influence on fertility. This paper focuses on evaluating the important factors that is responsible for age of $1^{\text {st }}$ birth for ever-married females in Bangladesh. In this study, multivariate techniques have been employed to examine the factors that are responsible for the participant's age at $1^{\text {st }}$ birth using BDHS-2014 data. The findings indicate that consciousness factor, fertility factor, family planning factor, and occupational factor are a major influence of the age at $1^{\text {st }}$ birth. The study also used discriminant analysis which shows that $70.1 \%$ of total outcome were appropriately categorized in line with factor scores derived from factor analysis. Findings indicate that: there is a dynamic framework for first childbearing decision-making, along with a couple's understanding of population development, fertility, couple's level of schooling, and mother's engagement in the workforce. This study enables researchers to estimate future policy implications and fertility behavior, particularly in developing countries such as Bangladesh.
\end{abstract}

\section{Keywords}

First Birth, Women, Bangladesh, Population, Multivariate Techniques

\section{Introduction}

The age at which childbearing begins impacts the number of children a lady carries during her time of reproduction. Therefore, the age of the mother from the onset of birth affects all outnumbers of births she might have in her lifetime, which affects the population's growth, and future development. Early childbearing can have an antagonistic effect on the strength of the mother and the newborn child, the family's monetary assistance. Maternal deaths are among the highest in the world's South East Asia region and a woman dies from pregnancy complications about every two minutes.

In 2017, 295,000 women died from complications linked to pregnancy and newborn deaths were 2.5 million (WHO, 2019; Hug et al., 2019). Increasing numbers of research show that family well-being depends on how early childbearing starts and how promptly it continues. Expansion of contraceptive use, improved education for women and workforce participation have been claimed, as the reasons for delayed first equality have also led to a decrease in fertility in previous studies. Scarcely any different investigations additionally propose the impact of instruction, 
riches, race, living spot (urban/provincial), on age from the outset birth. Women's motherhood differs on the basis of women's education level as ladies who have completed her educational degrees have their first child later than ladies who have finished at lower levels. The impact of work was additionally seen in past examinations. The discoveries bolster the recommendation that various determining factor become a force to be reckoned with at various gatherings, including training.

Looking at the regenerative conduct of Tanzanian ladies, it has been gotten that the instruction of a lady, the spot of the home, and religion assume the best jobs in affecting age from the start birth in Tanzania. This examination moreover found that one percent of all initially live births came about because of pre-marriage originations. On account of financial status and race, past examinations uncovered that monetary conditions are significant full-scale level powers driving the progress to parenthood. The outcomes demonstrate that monetary conditions are critical indicators of the two results, with financial conditions for females having impacts unique in relation to those for guys.

A comparison of data from the BDHS surveys of 2004 and 2007 shows a little change in median age for women at her first childbirth. As with other developing countries, socio-economic conditions in Bangladesh also play a critical role in fertility. The most important variation in previous studies has been explained by family pressure among socioeconomic and cultural determinants. It is extremely hard to decrease fruitfulness in complex socio-social settings in provincial Bangladesh. Recent studies have examined fertility trends to expose the most important factors inhibiting and enhancing fertility for married teenagers in Bangladesh. Highest education level among all the surrounding covariates is hypothesized as the most important factor inhibiting fertility for adolescents. In most previous studies, the researchers attempted to classify major determinants of fertility or occasionally differentials by analyzing age determinants at first birth. This research attempted to investigate the underlying factors that decide the age of the respondent at first birth, rather than the normal analysis of regression.

\section{Literature Review}

Improving the endurance and prosperity of mothers will not just increment the strength of social orders, yet it will likewise diminish imbalance and destitution (Yeaseen, 2017). Having the first birth is one of the most critical occasions in a women's life. It demonstrates the start of concentrated obligations of parenthood and childcare. Early commencement of first birth decreases personal satisfaction because of the duties of parenthood and childcare. Early passage into parenthood stretches the regenerative period and along these lines expands fertility. It is a significant determinant of enormous family size just as quick populace development. Youthful mothers and fathers may likewise be less versatile even with the physical, enthusiastic, and monetary burdens associated with bringing up children and have less pressure buffering assets (Nicola, 2013). It has been archived that exceptional maternal and fatherly age influences adversely fecund ability, and the physiological capacity of couples to conceive (Larsen \& Yan, 2000; Sartorius \& Nieschlag, 2010). Around one-fourth of young ladies matured 10-14 in developing nations are not taken on school, and every year in excess of 14 million young ladies aged 15-19, the greater part of whom are not in school conceive an offspring. A developing number of studies propose that family prosperity is molded by how soon childbearing is started and how quickly it continues. Extension of contraceptive use, increment in women's education and work power investment have been contended as the explanations behind deferred first equality likewise a purpose behind fertility decrease in past examinations (Abbasi-Shavazi, 2002; Erfani, 2008). Examinations between Eastern and Western Europe are exceptionally compelling because of the longstanding example of prior female marriage and fertility in the East, which suggests less choice into early motherhood (Frejka, 2004). In Bangladesh, the middle age from the first birth is around 18 years overall age companions, with the exception of women age 20-24 years, whose middle age from the outset birth is 19 years, showing a slight increment in the age from the first birth as of late. A correlation of information from the 2004 and 2007 BDHS reviews shows a slight increment in the middle age from the first birth for women in all age groups (Mitra, et al., 2009). Like other developing nations, in Bangladesh, the socio-affordable example additionally assumes a fundamental job on fertility. Among financial and social determinants, family pressure clarified the hugest change in previous studies (Haque, 2009). It is extremely hard to diminish fertility in complex socio-social settings in rustic Bangladesh. A few procedures are theorized to underlie this relationship between early parenthood and poorer later health. For women, pregnancy, parturition, and lactation present physiological difficulties that might be more prominent for youthful mothers (Pirkle, 2014). The quality of the negative relationship between female age and fertility has seen as considerably more grounded in women who have never imagined, since they may experience the ill effects of essential barrenness (Steiner \& Jukic, 2016). Moreover, men play a significant job in deferring parenthood due to having deficient information about conceptive life expectancy and delaying shaping organizations and childbearing with women (Hammarberg, et al., 2017). 


\section{Data and Variables}

\subsection{Data source:}

The Data for the study collected from Demographic Health survey (DHS), 2014.

\subsection{Description of the Variables:}

For this study Total number of children ever born of women in Bangladesh is used as the dependent Variable and the predictor variables that have been included for this analysis which are Division, Age 5-years group, Type of place of residence, respondent's educational qualification, Religion, Wealth index, Husband/partner's education level, Husband/partner's occupation, working status of respondent, media exposure, husband age, age at 1st marriage, contraceptive use, etc. For the appropriateness of this examination, a few factors are recorded and simultaneously new factors made by consolidating data of certain factors rather than the factors with their unique codes.

\section{Methodology}

For a larger contingency table, some other method is needed. Chi-squared tests of statistical independence supplies this need. To determine the significant factor in determining the age at first birth of Bangladeshi women factor analysis has been used in this study. The main goal is to identify the most relevant factors from a set of possible explanatory variables. Discriminant analysis is also used in this study.

\subsection{Analysis}

In this study, maximum respondent’s current age lies in 25-30 years period (Figure 1).

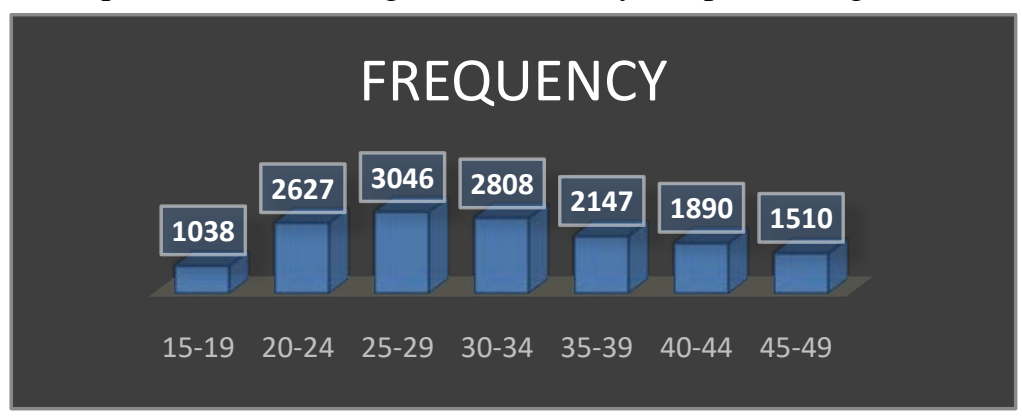

Figure 1. Age of Respondents (Source: Estimated).

In our study, age at first birth is ranging from 10 up to 49 years. But $75.9 \%$ has given birth before 20 years old (Table 1).

Table 1. Frequency Distribution of Age

\begin{tabular}{cccc}
\hline & Frequency & Percent & Cumulative Percent \\
\hline 10-19 years & 11,352 & 75.3 & 75.3 \\
20-29 years & 3,588 & 23.8 & 99.2 \\
30-39 years & 123 & 0.8 & 100 \\
40-49 years & 3 & 0 & 100 \\
Total & 15,066 & 100 & \\
\hline
\end{tabular}

Source: Estimated.

In this study, the residential status stated that $66.3 \%$ are from rural life. In case of division, the figure of age at first birth of married woman is $17.2 \%$ in Dhaka, whereas $16.1 \%$ in Chittagong division. Like other countries, our nation is not affected through ethnicity or minority. But religious sector is still a concern in our work. The lion's portion is possessed through Muslim societies.

Wealth index is a relevant and far reaching drivers for woman occurring child marriage. On our study, $62.4 \%$ are in middle or rich families. Education level of respondents is quite satisfactory as the frequency of literate respondents is staggering in primary and secondary level for aged at first birth women (Figure 2). 


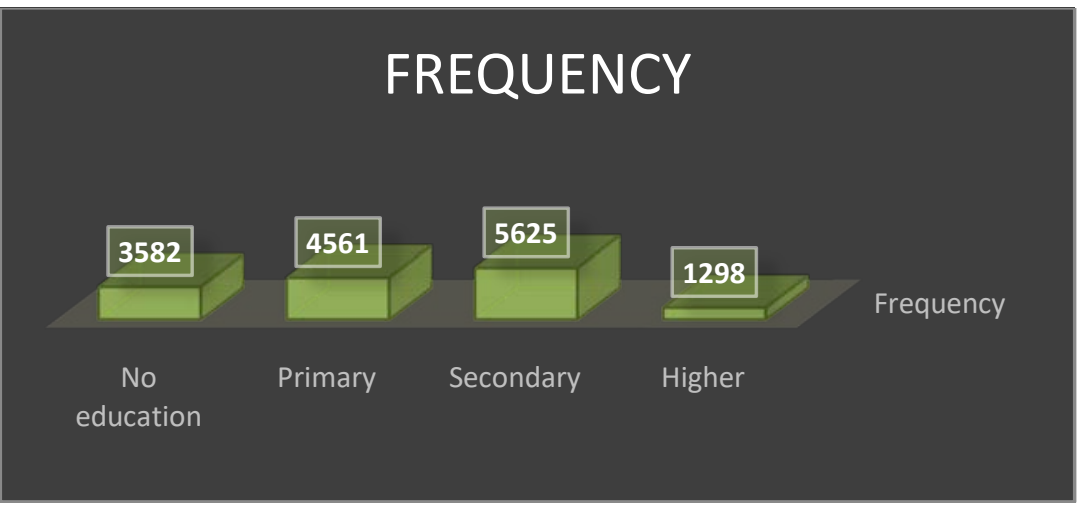

Figure 2. Frequency Distribution of Level of Education (Source: Estimated).

Education of husband is also crucial for alleviating ignorance and superstition prevailing in our society. But our study found the level of uneducated husbands is still higher than primary or secondary level accomplished groups (Figure 3).

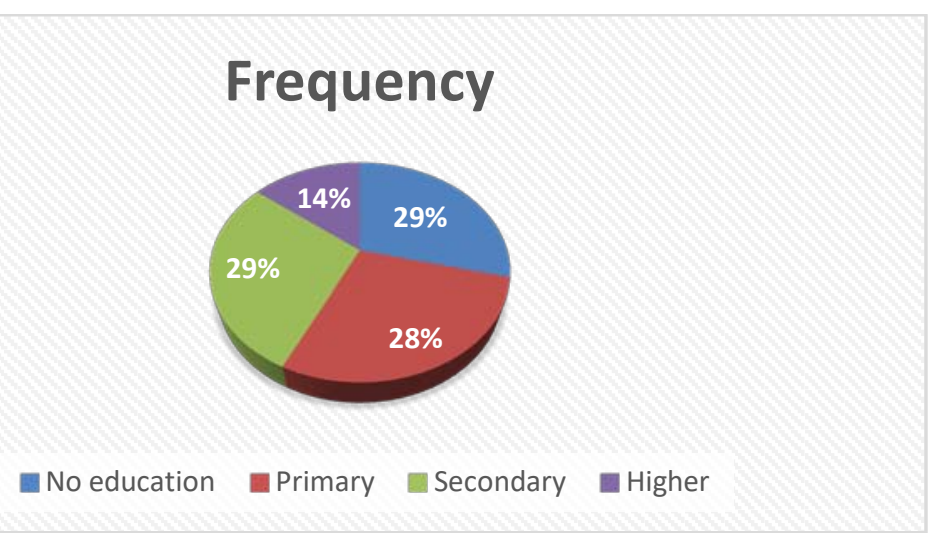

Figure 3. Frequency Distribution of Level of Education of Households (Source: Estimated).

Respondent's participation in workforce is a premium factor for women or child related issues or problems. 31.6\% percent are already engaged in the workplace of employment. The lifestyle and job situation of respondent's husband is also sometimes liable in health-related issue for maternal or child sectors. Manually skilled persons are in a rising number than others category (Table 2).

Table 2. Frequency Distribution of Lifestyle and Job

\begin{tabular}{cccc}
\hline & Frequency & Percent & Cumulative Percent \\
\hline Did not work & 123 & 0.8 & 0.8 \\
Professional/technical/managerial & 1,487 & 9.9 & 10.7 \\
Sales & 2,969 & 19.7 & 30.4 \\
Agricultural—self-employed & 1,498 & 9.9 & 40.3 \\
Agricultural-employee & 2,672 & 17.7 & 58.1 \\
Household and domestic & 14 & 0.1 & 58.2 \\
Services & 1,156 & 7.7 & 65.8 \\
Skilled manual & 4,808 & 31.9 & 97.7 \\
Unskilled manual & 339 & 2.3 & 100 \\
& & & \\
\hline
\end{tabular}

Source: Estimated.

One of the latent factors for taking birth early is immaturity of husband. On our dissertation, most of the husband's age is more than 25 years old (Table 3 ). 
Shanjida Chowdhury, Mahfujur Rahman, Nurul Mohammad Zayed, Shahiduzzaman Khan Shahi

Table 3. Frequency Distribution of Immaturity of Husbands

\begin{tabular}{cccc}
\hline & Frequency & Percent & Cumulative Percent \\
\hline 16-25 years & 911 & 6 & 6 \\
26-35 years & 5,006 & 33.2 & 39.3 \\
36-45 years & 4,509 & 29.9 & 69.2 \\
$>$ 45 years & 4,640 & 30.8 & 100 \\
Total & 15,066 & 100 & \\
\hline
\end{tabular}

Source: Estimated.

Contraceptive use and its prevalence is also a crucial factor. Out of 15,066 respondents, 66.1 percent are used currently or before of contraceptive methods. It is an advantage of today's age that radio, newspapers and television has provided prime work on family planning protection. In our study, only $21 \%$ have exposed with media. The time span of marriage is a vital part for anyone's life. So, our study reveals maximum occurrences of first marriage under 20 years old (Table 4$)$.

Table 4. Frequency Distribution of Age of First Marriage

\begin{tabular}{lccc}
\hline & Frequency & Percent & Cumulative Percent \\
\hline 10-20 years & 14,276 & 94.8 & 94.8 \\
21-30 years & 770 & 5.1 & 99.9 \\
31-40 years & 17 & 0.1 & 100 \\
41-49 years & 3 & 0 & 100 \\
\hline
\end{tabular}

Source: Estimated.

\subsection{Bivariate analysis}

Result of the bivariate analysis, shown in Table 5 in appendix. From the result of bivariate analysis, in case of Dhaka division, the percentage is slightly higher (17.20\%) for aged at first birth of married woman than Chittagong (16.10\%) or other division. For each age-group of child at first birth, the number of urban persons is much lower than rural respondents.

Overall 23.8\% while $19.2 \%$ for 10-19 years age group has not seen the light or power of education. Also, 25.10\% has assured primary level education and $28.50 \%$ has completed their secondary level. But this increasing manner is not seen in higher level as it drops down into $2.5 \%$ for $10-19$ years but rises in 5.7\% for 20-29 age group. In case of Muslim, the number of respondents has surpassed in each age-group than other religions. Overall, the social class of ricer level is $20.9 \%$ is higher than others. But in cell-wise, middle class for 10-19 years old is highest than other cell frequency. Education level of respondent's husband is still higher for illiterate society. But in age-group, the younger (i.e., 10-19 years) group is engrossed in illiteracy. Also, this youngest group is higher in secondary level. The power of media in family planning is now study variable in recent decades. In case of family planning, most respondents argue that the power of media is not active for maintain or taking action in family planning (79.70\%). Age at first marriage is also entangled before age at first birth for married woman. Still teenage or adolescent or child marriage is whereas a problem in our society is also observed in our study as $94.8 \%$ has knitted in nuptial stage before 20 years. Taking contraceptives after marital stage is not a new word in today's world as $66.1 \%$ has already or using contraceptives. More precisely, $50.4 \%$ or in a half of population aged under 20 years have experienced with the stages of contraception and its position.

\subsection{Multivariate analysis}

In this paper PCA with varimax rotation is showing where rotated loadings 0.5 or higher to confirm that independent variables identified are represented by a particular factor of a rotated matrix (Table 5). From factor analysis, four components were extracted. In this study, factor 1 coincides with 3 variables, Moher's educational level (0.811), husband's educational level (0.787) and wealth index (0.72). As age at first birth increases with increased level of education as well as awareness, so this factor named as "consciousness factor". Again, another motive of such naming is this factor is negatively related with place of residence $(-0.451)$, that specifies the differential status of consciousness on residence wise as compared to urban women, rural women have earlier first birth.

On factor 2 it associated with Husband's age (0.883) and age-group of respondents (0.891), which indicates the 
fecundity factor.

Table 5. Rotated Component Matrix

\begin{tabular}{|c|c|c|c|c|}
\hline \multicolumn{5}{|c|}{ Component } \\
\hline Variables & 1 & 2 & 3 & 4 \\
\hline Age in 5-year groups & -0.301 & 0.891 & -0.031 & -0.008 \\
\hline Division & -0.155 & -0.027 & 0.382 & -0.232 \\
\hline Type of place of residence & -0.451 & -0.228 & 0.212 & -0.457 \\
\hline Highest educational level & 0.811 & -0.149 & 0.089 & -0.139 \\
\hline Religion & 0.007 & 0.029 & 0.356 & 0.027 \\
\hline Wealth index & 0.720 & 0.327 & -0.204 & 0.144 \\
\hline Husband/partner’s education level & 0.787 & 0.125 & 0.036 & -0.155 \\
\hline Husband/partner's occupation (grouped) & -0.269 & -0.306 & -0.473 & 0.332 \\
\hline Respondent currently working & -0.184 & 0.115 & 0.424 & 0.576 \\
\hline media exposure & 0.478 & 0.145 & -0.058 & 0.247 \\
\hline husband age & -0.289 & 0.883 & -0.031 & -0.012 \\
\hline age at 1st marriage & 0.382 & 0.219 & 0.315 & -0.254 \\
\hline contraceptive & 0.075 & -0.144 & 0.523 & 0.422 \\
\hline
\end{tabular}

Extraction Method: Principal Component Analysis., Rotation Method: Varimax with Kaiser Normalization. Rotation converged in 7 iterations.

Source: Estimated.

Family planning impacts fertility through the use of contraceptives. Family planning was the third factor investigated for age at first birth; due to a strong association with pregnancy status (0.523) and age at first marriage (0.315). High factor loading has been seen for mother's employment status. This signifies the ground for working mothers to have children later.

Our final factor associates 1 variable named respondent's working status. So, fourth and final factor is the occupational factors.

This study considers the factors that have Eigenvalue more than 1 and these four factors take out from factor analysis, which elucidate the variation of age at first birth by $20.643 \%, 15.138 \%, 8.846 \%$, and $8.154 \%$ and altogether four factors explained $52.782 \%$ of total variation (Table 6).

Table 6. Results of Discriminant Analysis

\begin{tabular}{|c|c|c|c|c|c|}
\hline \multicolumn{3}{|c|}{ Age at first birth (dichotomous) } & \multicolumn{2}{|c|}{ Predicted Group Membership } & \multirow[t]{2}{*}{ Total } \\
\hline & & & $<$ or equal 20 & $>21$ & \\
\hline \multirow[t]{4}{*}{ Original } & Count & $<$ or equal 20 & 12,501 & 0 & 12,501 \\
\hline & & $>21$ & 736 & 1,829 & 2,565 \\
\hline & $\%$ & $<$ or equal 20 & 100 & 0 & 100 \\
\hline & & $>21$ & 28.7 & 71.3 & 100 \\
\hline
\end{tabular}

Source: Estimated.

The Discriminant Analysis was used to study the relationship between the factors explored in factor analysis and the mother's age at first birth, as presented in Table 6. Mothers who have entered child-bearing status at age (under 20) and others (upper than 20) are considered to be two groups for this analysis. The purpose behind these clusters is to know the efficacy of the study findings for adolescent mothers precisely and to avoid computational complexity (see Table 6). Overall, $95.1 \%$ of the mother's age at first birth was correctly predicted on the basis of the discriminant function analysis. For mothers of lower age and adolescents (below 20), 28.7\% of mothers were correctly classified, while for other mothers (above 20), 71.3\% were correctly classified. In other words, the sensitivity of the discriminant function was $28.7 \%$ and the specificity was $71.3 \%$.

\section{Conclusion and Policy Recommendations}

First birth is a step to motherhood for a woman; it is also a significant predictor of mother's health. In the present 
analysis, multivariate techniques have been employed to examine the fundamental factors that decide the age of the respondent at first birth using BDHS-2014 data. The findings indicate that in Bangladesh literacy factor, fecundity factor, family planning factor, occupational factors are a major cause of the age at first birth of women. Acceptability of the results was established by a discriminant analysis, which indicates that $70.1 \%$ of the total observations were categorized correctly according to the factor scores found from the factor analysis. The greatest amount of variance, according to factor analysis, is explained by the consciousness variable. It has been shown that qualified mothers often have fewer children and are mindful of the benefits of delayed childbearing. Nevertheless, in Bangladesh's socio-economic background, the degree of education of women still depends on the framework of the family/socio-economic status due to religious and other social perspectives. Despite improvement of the women's education scenario, significant improvement of the fertility scenario is not feasible. Also, it also relates to the involvement of mothers in the labor force. The job status of the mother has a substantial effect on the age at first birth. This also has a certain connection with mothers' jobs, if trained mothers do not have an adequate employment, they would not be involved in higher jobs.

Steps should be taken to enhance spousal coordination on family planning, to encourage small family expectations and an optimal pregnancy spacing. Special attention should be paid to newly-wed couples and the adoption of reproductive health services among teenagers. Overall, raising awareness through counseling and social events will be a safe way to protect mothers from early childbearing. The results of this study indicate that women should be married at a later age. Or, the government may take the necessary measures to resist early marriage of women. The influence of mass media is vast; it can be used prominently to make rapid changes to any socio-cultural or socio-economic problem.

\section{Acknowledgement}

Special thanks are given to World Bank for giving access to their online version of World Development Indicators (WDI), the World Bank database.

\section{References}

Abbasi-Shavazi, M. M. (2002). Revolution, war and modernization: Population policy and fertility change in Iran. Journal of Population Research, 19(1), 25-46.

Erfani, A. (2008). Rapid fertility decline in Iran: Analysis of intermediate variables. Journal of Biosocial Science, 40(3), 459-478.

Frejka, T. J.-P. (2004). “Baltic region,” in Tomas Frejka and Jean-Paul Sardon (eds.). In Childbearing Trends and Prospects in Low-Fertility Countries. (pp. 253-270). Dordrecht: Kluwer Academic Publishers.

Hammarberg, K., et al. (2017). Men’s knowledge, attitudes and behaviours relating to fertility. Hum Reprod, 23, 458-80.

Haque, M. (2009). Socioeconomic Determinants of Age at First Birth in Rural Areas of Bangladesh. Asia Pacific Journal of Public Health, 21(1), 104-111.

Hug, L., Alexander, M., You, D., Alkema, L., and for Child, U. I. A. G. (2019). National, regional, and global levels and trends in neonatal mortality between 1990 and 2017, with scenario-based projections to 2030: a systematic analysis. The Lancet Global Health, 7(6), e710-e720.

Lappegård, T. (2005). The Multifaceted Impact of Education on Entry into Motherhood. European Journal of Population, 21, 31-49.

Larsen, U. and Yan, S. (2000). The age pattern of fecundability: an analysis of French Canadian and Hutterite birth histories. Social biology, 47(1-2), 34-50.

Mitra, et al. (2009). National Institute of Population Research and Training (NIPORT). Bangladesh: Bangladesh and Calverton, Maryland, USA: National Institute of Population Research and Training, Mitra and Associates, and Macro International.

Nicola, B. (2013). Family trajectories and health: A life course perspective. European Journal of Population/Revue européenne de Démographie, 29(4), 357-385.

Nour, N. M. (2006). Health consequences of child marriage in Africa. Emerging Infectious Diseases, 12(11), 1644.

Pirkle, C. M.-V. (2014). Early maternal age at first birth is associated with chronic diseases and poor physical perfor- 
mance in older age: Cross-sectional analysis from the International Mobility in Aging Study. BMC Public Health, 14(293).

Sartorius, G. A. and Nieschlag, E. (2010). Paternal age and reproduction. Human Reproduction Update, 16(1), 65-79. https://doi.org/10.1093/humupd/dmp027.

Steiner, A. Z. and Jukic, A. M. Z. (2016). Impact of female age and nulligravidity on fecundity in an older reproductive age cohort. Fertility and sterility, 105(6), 1584-1588.

World Health Organization. (2019). Trends in maternal mortality 2000 to 2017: estimates by WHO, UNICEF, UNFPA, World Bank Group and the United Nations Population Division.

Yeaseen Chowdhury, A. S.-r. (2017). Factors Affecting Age for First Birth: An Exploratory Analysis on Bangladeshi Women. International Journal of Research Studies in Medical and Health Sciences, Volume 2(Issue 7), 31-37.

\section{Appendix}

Table 1. Result of Bivariate analysis

\begin{tabular}{|c|c|c|c|c|c|c|}
\hline & & 10-19 Years & 20-29 Years & 30-39 Years & 40-49 Years & Total \\
\hline \multirow{7}{*}{ Division } & Barisal & $9.00 \%$ & $2.90 \%$ & $0.10 \%$ & $0.00 \%$ & $12.00 \%$ \\
\hline & Chittagong & $12.20 \%$ & $3.80 \%$ & $0.10 \%$ & $0.00 \%$ & $16.10 \%$ \\
\hline & Dhaka & $12.50 \%$ & $4.50 \%$ & $0.20 \%$ & $0.00 \%$ & $17.20 \%$ \\
\hline & Khulna & $11.30 \%$ & $3.00 \%$ & $0.10 \%$ & $0.00 \%$ & $14.40 \%$ \\
\hline & Rajshahi & $11.10 \%$ & $3.00 \%$ & $0.10 \%$ & $0.00 \%$ & $14.30 \%$ \\
\hline & Rangpur & $11.40 \%$ & $2.90 \%$ & $0.10 \%$ & $0.00 \%$ & $14.40 \%$ \\
\hline & Sylhet & $7.80 \%$ & $3.70 \%$ & $0.10 \%$ & $0.00 \%$ & $11.60 \%$ \\
\hline \multirow{3}{*}{$\begin{array}{c}\text { Place of } \\
\text { Residence }\end{array}$} & Urban & $22.90 \%$ & $10.30 \%$ & $0.40 \%$ & $0.00 \%$ & $33.70 \%$ \\
\hline & Rural & $52.40 \%$ & $13.50 \%$ & $0.40 \%$ & $0.00 \%$ & $66.30 \%$ \\
\hline & No Education & $19.20 \%$ & $4.40 \%$ & $0.20 \%$ & $0.00 \%$ & $23.80 \%$ \\
\hline \multirow[t]{2}{*}{ Education } & Primary & $25.10 \%$ & $5.10 \%$ & $0.10 \%$ & $0.00 \%$ & $30.30 \%$ \\
\hline & Secondary & $28.50 \%$ & $8.70 \%$ & $0.10 \%$ & $0.00 \%$ & $37.30 \%$ \\
\hline \multirow{7}{*}{ Religion } & Higher & $2.50 \%$ & $5.70 \%$ & $0.40 \%$ & $0.00 \%$ & $8.60 \%$ \\
\hline & Islam & $68.90 \%$ & $20.60 \%$ & $0.70 \%$ & $0.00 \%$ & $90.20 \%$ \\
\hline & Hinduism & $6.10 \%$ & $2.80 \%$ & $0.10 \%$ & $0.00 \%$ & $9.00 \%$ \\
\hline & Buddhism & $0.30 \%$ & $0.30 \%$ & $0.00 \%$ & $0.00 \%$ & $0.60 \%$ \\
\hline & Christianity & $0.10 \%$ & $0.10 \%$ & $0.00 \%$ & $0.00 \%$ & $0.20 \%$ \\
\hline & Other & $0.00 \%$ & $0.00 \%$ & $0.00 \%$ & $0.00 \%$ & $0.00 \%$ \\
\hline & Poorest & $15.40 \%$ & $2.90 \%$ & $0.10 \%$ & $0.00 \%$ & $18.40 \%$ \\
\hline \multirow{3}{*}{ Wealth Index } & Poorer & $15.70 \%$ & $3.40 \%$ & $0.10 \%$ & $0.00 \%$ & $19.20 \%$ \\
\hline & Middle & $16.30 \%$ & $4.00 \%$ & $0.00 \%$ & $0.00 \%$ & $20.30 \%$ \\
\hline & Richer & $15.60 \%$ & $5.20 \%$ & $0.10 \%$ & $0.00 \%$ & $20.90 \%$ \\
\hline \multirow{5}{*}{ Education Level of Respondent's Husband } & Richest & $12.40 \%$ & $8.40 \%$ & $0.40 \%$ & $0.00 \%$ & $21.20 \%$ \\
\hline & No Education & $23.80 \%$ & $5.00 \%$ & $0.10 \%$ & $0.00 \%$ & $28.90 \%$ \\
\hline & Primary & $23.30 \%$ & $4.80 \%$ & $0.10 \%$ & $0.00 \%$ & $28.20 \%$ \\
\hline & Secondary & $21.50 \%$ & $7.00 \%$ & $0.10 \%$ & $0.00 \%$ & $28.60 \%$ \\
\hline & Higher & $6.70 \%$ & $7.10 \%$ & $0.50 \%$ & $0.00 \%$ & $14.30 \%$ \\
\hline Media & No & $62.10 \%$ & $17.10 \%$ & $0.50 \%$ & $0.00 \%$ & $79.70 \%$ \\
\hline \multirow[t]{2}{*}{ Exposure } & Yes & $13.30 \%$ & $6.70 \%$ & $0.30 \%$ & $0.00 \%$ & $20.30 \%$ \\
\hline & $10-20$ years & $75.20 \%$ & $19.20 \%$ & $0.30 \%$ & $0.00 \%$ & $94.80 \%$ \\
\hline Age at First & $21-30$ years & $0.10 \%$ & $4.60 \%$ & $0.40 \%$ & $0.00 \%$ & $5.10 \%$ \\
\hline \multirow[t]{2}{*}{ Marriage } & $31-40$ years & $0.00 \%$ & $0.00 \%$ & $0.10 \%$ & $0.00 \%$ & $0.10 \%$ \\
\hline & $41-49$ years & $0.00 \%$ & $0.00 \%$ & $0.00 \%$ & $0.00 \%$ & $0.00 \%$ \\
\hline Taking Contraceptives & No used & $25.00 \%$ & $8.50 \%$ & $0.40 \%$ & $0.00 \%$ & $33.90 \%$ \\
\hline after Marital Stage & Use/used & $50.40 \%$ & $15.30 \%$ & $0.40 \%$ & $0.00 \%$ & $66.10 \%$ \\
\hline
\end{tabular}

